\title{
Laboratory aspects of intermittent drug therapy
}

\author{
D. A. Mitchison \\ JEAN M. Dickinson

\begin{abstract}
MRC Unit for Laboratory Studies of Tuberculosis, Royal Postgraduate Medical School, DuCane Road, London, W12 0HS
\end{abstract}

\begin{abstract}
Summary
The drug-parasite relationships for isoniazid and rifampicin have been investigated, using cultures of $M$. tuberculosis and infected guinea-pigs.

It is remarkable that there appear to be two entirely different mechanisms involved in intermittent chemotherapy with isoniazid and rifampicin. With isoniazid, any escape from the influence of the drug leads to diminished efficacy. On the other hand, with rifampicin, it is just this escape that promotes higher efficacy.
\end{abstract}

For the past few years a number of antibacterial drugs used in the treatment of tuberculosis have been screened for their suitability in intermittent regimens of chemotherapy (Dickinson \& Mitchison, 1966a, 1966b, 1970; Dickinson, Ellard \& Mitchison, 1968). Experiments were done in vitro and in experimental tuberculosis of the guinea-pig. More recently this work has been extended to investigate the details of the drug-parasite relationship for isoniazid and rifampicin.

\section{In vitro experiments}

\section{Methods}

A log-phase culture of $M$. tuberculosis strain H37Rv in 7H9 Tween-albumin liquid medium, was exposed to one of the drugs in a concentration approximately ten times the MIC After the desired exposure period, the drug was removed by filtration through a cellulose membrane filter and the bacilli were washed several times and then re-suspended in drug-free medium The effects of the pulsed exposure were evaluated by serial viable counts and, with rifampicin, by measuring the uptake of ${ }^{14} \mathrm{C}$ uridine. Uridine uptake is a direct measure of the antibacterial activity of rifampicin since it measures RNA formation and rifampicin acts by inhibiting bacterial DNA dependent RNA polymerase (Hartmann et al., 1967; Wehrli et al., 1968a, 1968b; Sippel \& Hartmann, 1968; Umezawa et al., 1968).

\section{Results}

After exposure to a bactericidal drug, there was a period of several days (the lag period) before growth

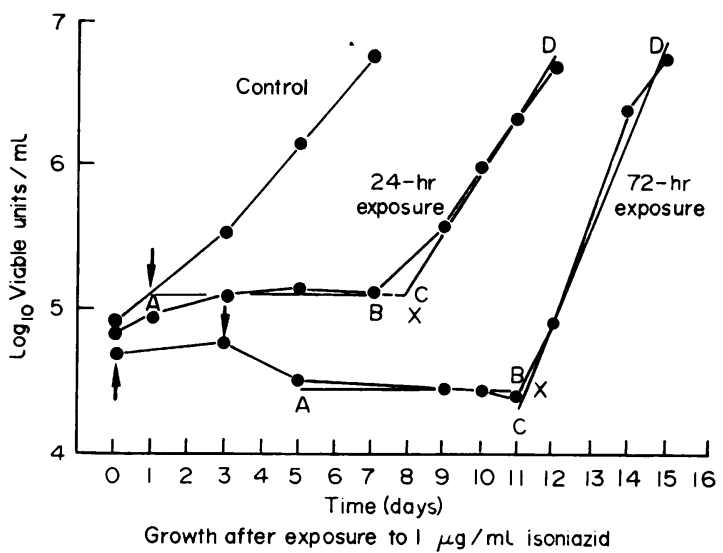

FIG. 1. Growth during and after exposure to $1 \mu \mathrm{g} / \mathrm{ml}$ isoniazid. $\uparrow$, Addition of isoniazid; $\downarrow$, removal of isoniazid by filtration.

restarted. Figure 1 shows the effects of exposure to isoniazid $1 \mu \mathrm{g} / \mathrm{ml}$ for 24 or $72 \mathrm{hr}$. There was a lag period of 7 days following a 24-hr exposure and of 6 days following a 72-hr exposure. Bactericidal activity was evident only during the $72-\mathrm{hr}$ exposure.

Figure 2 shows the results of exposure to rifampicin $0 \cdot 2 \mu \mathrm{g} / \mathrm{ml}$ for 24 or $96 \mathrm{hr}$. There was marked bactericidal activity during the 24-hr exposure, but recovery started within a day or two after the drug was removed. The lag periods encountered after pulsed exposures to various drugs are summarized in Table 1. No lag occurred after exposure to the bacteriostatic drugs thiacetazone and thiocarlide. The remaining drugs are all bactericidal. With most of these, the maximum lag period found, after exposures of 24 and $96 \mathrm{hr}$, was 4-9 days. Furthermore, they were only bactericidal when the exposure period was $24 \mathrm{hr}$ or more. Rifampicin was exceptional because its bactericidal activity was evident during exposures as short as $6 \mathrm{hr}$ and because the maximal lag period was only 2-3 days-the organisms were quickly affected but also recovered quickly.

In interpreting these experiments, our first hypothesis was that a drug would be particularly effective 


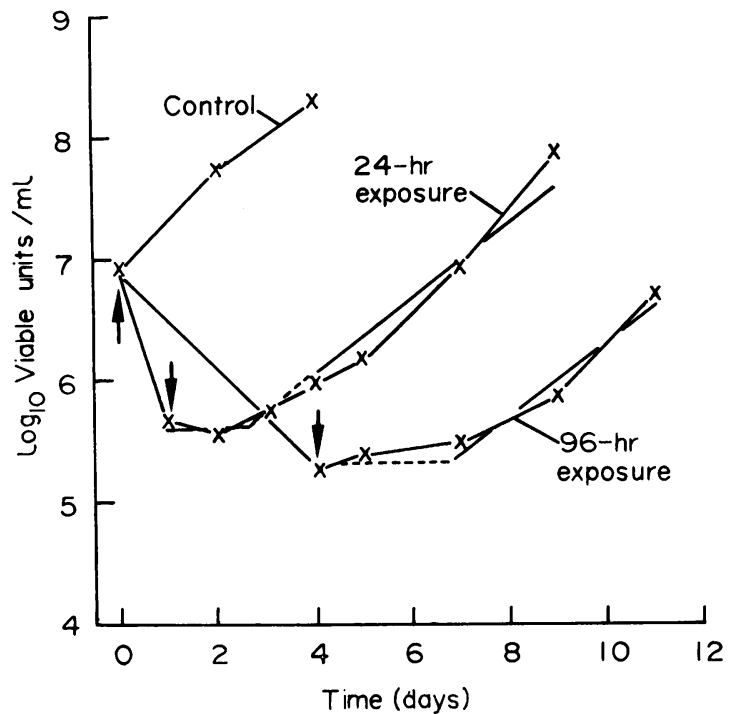

Growth after exposure to $0.2 \mu \mathrm{g} / \mathrm{ml}$ Rifampicin

Fig. 2. Growth during and after exposure to $0.2 \mu \mathrm{g} / \mathrm{ml}$ rifampicin. $\uparrow$, Addition of rifampicin; $\downarrow$, removal of rifampicin by filtration.

TABLE 1. Lag periods after pulsed exposures to antibacterial drugs

\begin{tabular}{lcccc}
\hline Drug & $\begin{array}{c}\text { Concentration } \\
\text { of drug } \\
(\mu \mathrm{g} / \mathrm{ml})\end{array}$ & \multicolumn{2}{c}{$\begin{array}{c}\text { Lag period (days) } \\
\text { after exposure for: }\end{array}$} \\
\cline { 3 - 5 } & 10 & $6 \mathrm{hr}$ & $\begin{array}{c}24 \mathrm{hr} \text { or more } \\
\text { (maximal) }\end{array}$ \\
\hline Thiacetazone & 10 & 0 & 0 \\
Thiocarlide & 10 & 0 & 0 \\
Isoniazid & 1 & 0 & $6-9$ \\
Ethionamide & 5 & 0 & 10 \\
Cycloserine & 100 & 0 & $4-8$ \\
Pyrazinamide & 50 & $5-9$ & $4-5$ \\
& 10 & (pH dependent) & \\
Ethambutol & 5 & 0 & $8-10$ \\
Streptomycin & $0 \cdot 2$ & $8-10$ & $2-3$ \\
Rifampicin & & $2-3$ & \\
\hline
\end{tabular}

in intermittent chemotherapy if the lag period produced were sufficiently long to prevent any growth of organisms between widely spaced doses of the drug. On this hypothesis, rifampicin would not be particularly suitable for intermittent use, since the lag period was always short and regrowth would occur between doses.

Several workers have shown that the effect of exposing a culture to isoniazid measured in different ways, is proportional to concentration times exposure period (Bourgeois, Dubois-Verlière \& Maël, 1958; Armstrong, 1960, 1965; Beggs \& Jenne, 1969). In other words, doubling the dose of isoniazid doubles the effect. Furthermore, Awaness (1971) has found that effects of repeated small exposures are cumulative provided that no regrowth occurs between them. Thus, we visualize the efficacy of intermittent isoniazid being dependent on the total dosage of drug given over the treatment period as long as the organisms do not recover between doses. The same effect may be obtained either by giving frequent small doses or less frequent large doses. On the other hand, there is a maximal lag of just under a week, irrespective of the size of the exposure of the bacilli. With once-weekly dosage we can therefore expect that some regrowth between doses occurs. When this happens, there would be a delay following each dose before any bactericidal action occurs, so that the overall bactericidal efficacy of the regimen would be greatly reduced. Furthermore, there would be a greater chance for drug resistance to emerge.

\section{Experiments in the guinea-pig}

Methods

Guinea-pigs were injected intra-muscularly with $M$. tuberculosis and disease was allowed to develop for 3 weeks. A 6-week period of treatment was the started with the drug concerned, given by gastrig intubation. At 9 weeks the visible extent of diseas in the organisms was assessed as the root-index of disease. Serum concentrations of the drug were also measured in the guinea-pigs at intervals after a dose

\section{Results}

The results of a typical experiment with isoniazid are shown in Table 2. The mean dosage and the interval between doses were both varied. As the interval between doses was spaced out, the dose size was increased proportionately. The mean root-index of disease for a group of six or seven guinea-pigs is shown in each cell of the Table. The dosage levels were chosen in this and in other experiments, to obtain an increasing response with increasing mean dosage and also to include dose levels that would give serum concentrations similar to those found in man.

TABLE 2. Root-indices of disease in guinea-pigs treated for 6 weeks with isoniazid

\begin{tabular}{|c|c|c|c|c|c|}
\hline \multirow{2}{*}{$\begin{array}{c}\text { Mean } \\
\text { daily } \\
\text { dose } \\
(\mathrm{mg} / \mathrm{kg})\end{array}$} & \multicolumn{4}{|c|}{ Interval between doses (days) } & \multirow{2}{*}{$\begin{array}{c}\text { Mean } \\
\text { root-index } \\
\text { of disease }\end{array}$} \\
\hline & 1 & 2 & 4 & 8 & \\
\hline $\begin{array}{l}0 \\
0 \cdot 5 \\
1 \\
2 \\
4\end{array}$ & $\begin{array}{c}- \\
1.03 \\
0.68 \\
0.64 \\
0.54\end{array}$ & $\begin{array}{c}- \\
0.89 \\
0.71 \\
0.60 \\
0.53\end{array}$ & $\begin{array}{c}- \\
0.76 \\
0.65 \\
0.61 \\
0.60\end{array}$ & $\begin{array}{l}-\overline{93} \\
0.86 \\
0.83 \\
0.85\end{array}$ & $\begin{array}{l}1.12 \\
0.90 \\
0.72 \\
0.67 \\
0.63\end{array}$ \\
\hline Mean & 0.72 & 0.68 & $0 \cdot 65$ & $0 \cdot 87$ & \\
\hline
\end{tabular}


We are particularly interested in the column means, which measure the average effect of increasing the interval between doses. These column means are shown for thiacetazone, ethionamide and streptomycin in Fig. 3. As would be expected from the in vitro results, the efficacy of thiacetazone decreased sharply as doses were spaced out, presumably because regrowth occurred between them. Treatment with streptomycin and ethionamide was less affected by intermittent administration.

Similar results are shown for isoniazid, ethambutol and rifampicin in Fig. 4. The efficacy of treatment increased as the doses were spaced out for ethambutol and, surprisingly, also for rifampicin. With isoniazid, there was little change in efficacy as the interval between doses was increased from 1-4 days, but a sharp decrease occurred when the interval was increased to 8 days. We assume that the breakdown that occurred with treatment every 8 days, arose because the maximal lag was exceeded so that regrowth occuried between doses.

\section{Intermittent treatment with isoniazid in man}

The rate of inactivation of isoniazid by acetylation is genetically controlled and patients can be clearly separated into slow and rapid inactivators. Serum concentrations in these two groups are shown in Fig. 5 (Tripathy, 1970); the exposure to isoniazid (concentration-time product) is three times greater in slow inactivators than in rapid inactivators. Patients

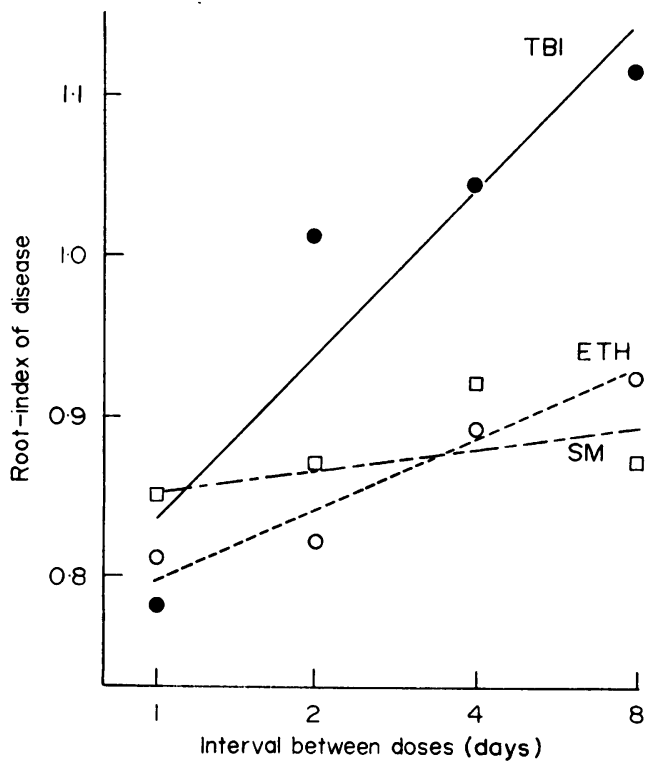

FIG. 3. Mean root-indices of disease related to interval between doses in guinea-pigs treated with thiacetazone, O; ethionamide, $O$; or streptomycin, $\square$.

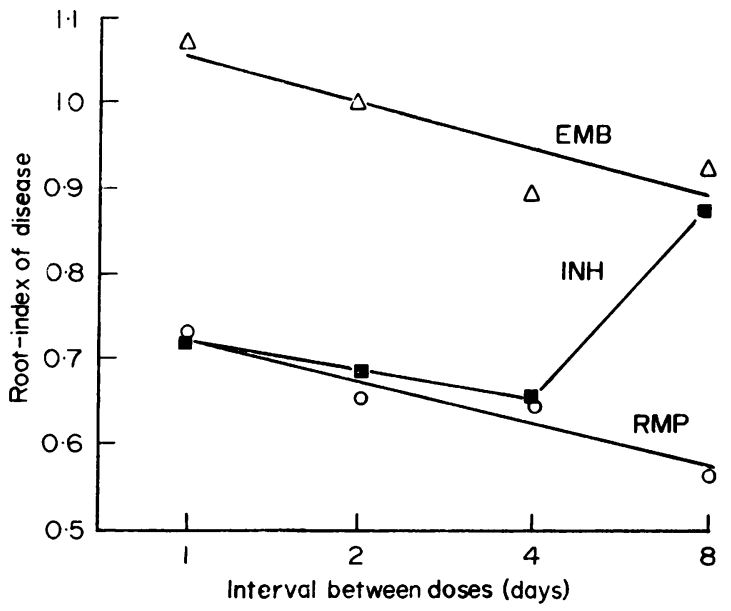

FIG. 4. Mean root-indices of disease related to interval between doses in guinea-pigs treated with isoniazid, $\square$; ethambutol, $\triangle$; or rifampicin, $\mathbf{O}$.

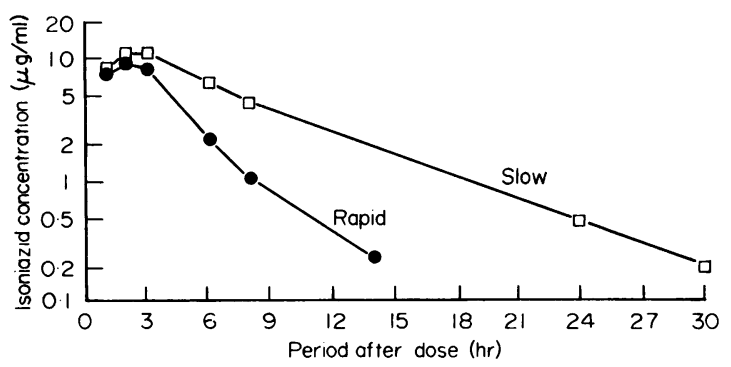

Fig. 5. Serum concentrations of isoniazid in slow and rapid inactivators after an oral dose of $15 \mathrm{mg} / \mathrm{kg}$ isoniazid.

were treated with twice-weekly or once-weekly high dosage isoniazid and streptomycin at the Tuberculosis Chemotherapy Centre, Madras (1970) and the results are summarized in Table 3 . The response to twice-weekly treatment was equally good in slow

TABLE 3. Status at 1 year of patients with pulmonary tuberculosis treated with twice-weekly or once-weekly isoniazid and streptomycin related to their rate of inactivation of isoniazid

\begin{tabular}{|c|c|c|c|c|}
\hline \multirow{3}{*}{$\begin{array}{l}\text { Interval } \\
\text { between } \\
\text { doses* } \\
\text { (days) }\end{array}$} & \multicolumn{4}{|c|}{ Rate of inactivation of isoniazid } \\
\hline & \multicolumn{2}{|r|}{ Slow } & \multicolumn{2}{|c|}{ Rapid } \\
\hline & $\begin{array}{c}\text { Total } \\
\text { patients }\end{array}$ & $\begin{array}{l}\text { Favourable } \dagger \\
\text { response }(\%)\end{array}$ & $\begin{array}{c}\text { Total } \\
\text { patients }\end{array}$ & $\begin{array}{l}\text { Favourable } \\
\text { response }(\%)\end{array}$ \\
\hline $\begin{array}{l}\text { wice-weekly } \\
\text { nce-weekly }\end{array}$ & $\begin{array}{l}82 \\
60\end{array}$ & $\begin{array}{l}92 \\
82\end{array}$ & $\begin{array}{l}35 \\
55\end{array}$ & $\begin{array}{l}91 \\
60\end{array}$ \\
\hline
\end{tabular}

* Isoniazid $15 \mathrm{mg} / \mathrm{kg}$ and streptomycin 0.75 or $1.0 \mathrm{~g}$. $\dagger$ Bacteriologically quiescent disease. 
and rapid inactivators, presumably because no regrowth occurred between doses and the effects of the doses were therefore cumulative. However, in onceweekly treatment, rapid inactivators responded much less well than slow inactivators. The explanation appears to be that, in both groups, some regrowth was occurring between doses. In the slow inactivators, the exposure following a single dose was sufficient to induce maximal lag. However, the exposure was insufficient to do this in the rapid inactivators, with the result that shorter lags would be induced, more regrowth would occur and each successive dose would have little bactericidal activity. If it were possible to increase the exposure to isoniazid in rapid inactivators, such that maximal lag would be induced, we could expect results as good as in slow inactivators and we would have effective once-weekly chemotherapy available.

An attempt was made to estimate what increase in exposure would be necessary in man using our guinea-pig system. The serum isoniazid curves in the guinea-pig are similar to those in rapid inactivators and the same dose, expressed as $\mathrm{mg} / \mathrm{kg}$, gives similar concentrations in the two species. The design of the guinea-pig experiment resembled the previous ones, but with doses of isoniazid given at intervals of 7 or $10 \frac{1}{2}$ days (Table 4). The guinea-pigs received one, two or three doses within a 24 -hr period to simulate the prolonged contact with the drug that occurs in slow inactivators. Considering guinea-pigs treated every 7 days, an increase from $10 \mathrm{mg} / \mathrm{kg}$ to 20 $\mathrm{mg} / \mathrm{kg}$, given in one or in two doses, produced the best response that could be obtained with weekly treatment; this was always slightly less good than in animals receiving maximally effective treatment. The results of treatment every $10 \frac{1}{2}$ days were less good and were unaffected by dose size. We therefore see that once maximal exposure has been achieved, no further benefits are obtained by increasing the dose size and that the response to isoniazid is determined by whether regrowth occurs between doses.

TABLE 4. Root indices of disease in the intermittent treatment with isoniazid of established tuberculosis in the guinea-pig (Untreated controls, 1.21; treated controls*, 0.49)

\begin{tabular}{ccccc}
\hline & \multicolumn{4}{c}{ Dosage with isoniazid } \\
\cline { 2 - 5 } $\begin{array}{c}\text { No. of } \\
\text { doses of } \\
\text { isoniazid }\end{array}$ & $\begin{array}{c}10 \mathrm{mg} / \mathrm{kg} \\
\text { every }\end{array}$ & $\begin{array}{c}20 \mathrm{mg} / \mathrm{kg} \\
\text { every }\end{array}$ & $\begin{array}{c}15 \mathrm{mg} / \mathrm{kg} \\
\text { every }\end{array}$ & $\begin{array}{c}30 \mathrm{mg} / \mathrm{kg} \\
\text { every }\end{array}$ \\
\hline 1 & 0.86 & 0.60 & 0.78 & 0.72 \\
2 & 0.65 & 0.57 & 0.70 & 0.75 \\
3 & 0.55 & 0.63 & 0.68 & 0.65 \\
Mean & 0.69 & 0.60 & 0.72 & 0.71 \\
Pt & $<0.001$ & 0.3 & 0.1 & 0.2 \\
\hline
\end{tabular}

* Treated with isoniazid $40 \mathrm{mg} / \mathrm{kg}$ twice-weekly.

$\dagger$ For association between number of doses and root-index of disease.
Applying these results to man, we can feel confident that only a modest increase in exposure to isoniazid is necessary in rapid inactivators. For instance, doubling of the exposure is probably all that would be necessary and this is likely to be achieved with sustained release preparations of the drug.

Mechanisms of intermittent treatment with rifampicin

On the hypothesis developed for isoniazid, it would seem improbable that rifampicin should be effective when given intermittently since the lag periods are exceptionally short. Nevertheless, rifampicin appeared particularly effective when given intermittently in the guinea-pig. An analysis of experiments in progress suggests that the following mechanisms are in operation:

(1) Using the uptake of uridine as a measure of antibacterial effect, the effect of pulsed exposures is proportional to (concentration) ${ }^{\mathbf{0 . 4}}$ times exposure period. This would result in a less than proportionate increase in effect as the dose size was increased. Such a relationship suggests that intermittent chemotherapy would be relatively ineffective.

(2) In the guinea-pig, as in man, an increase in theo dose size produces a more than proportionate rise in $\vec{P} \overrightarrow{ }$ serum concentrations and a prolongation of the hal life of the drug. This occurs because small doses are rapidly taken up in the liver and rapidly excreted ino the bile. The liver 'sink' and the biliary excretion $\stackrel{\mathbb{D}}{\mathrm{C}}$ mechanism become saturated as the dose size is in $\frac{0}{0} \overrightarrow{0}$ creased and excretion then occurs by the slower. urinary route. This effect favours intermittent chemo 0 therapy with large doses and, in the guinea-pig; more or less exactly counteracts the time-concentration relationship mentioned above.

(3) If successive doses of rifampicin are given at daily intervals, the bactericidal effect and the uptake of uridine decrease with each successive dose. However, if doses are spaced out, the organisms recover and start to grow. The effect of rifampicin is then maximal on these organisms. As a result, the overall bactericidal activity of daily and intermittent rifampicin with the same dose sizes, is similar. This mechanism accounts for the improved results obtained with intermittent regimens in the guinea-pig. However, there is a potential problem. The regrowth that occurs during intermittent administration is likely to promote the emergence of drug resistance when the bacterial population is high. The guineapig experiments are too short to measure this. It is therefore my guess that we will need to give a period of daily treatment with rifampicin before going on to an intermittent regimen.

\section{References}

Armstrong, A.R. (1960) Time-concentration relationships of isoniazid with tubercle bacilli in vitro. American Review of Respiratory Diseases, 81, 498. 
Armstrong, A.R. (1965) Further studies on the timeconcentration relationships of isoniazid and tubercle bacilli in vitro. American Review of Respiratory Diseases, 91, 440.

Awaness, A.M. (1971) Ph.D. Thesis, University of London. BegGS, W.H. \& JENNE, J.W. (1969) Isoniazid uptake and growth inhibition of Mycobacterium tuberculosis in relation to time and concentration of pulsed drug exposures. Tubercle, 50, 377.

Bourgeois, P., Dubois-Verlière, M. \& Mael, M. (1958) Etude de l'action descontinué de l'isoniazide sur le bacille de Kock par le méthode des cultures sur lames. Revue de Tuberculose et de Pneumologie, 22, 108.

Dickinson, J.M. \& Mitchison, D.A. (1966a) In vitro studies on the choice of drugs for intermittent chemotherapy of tuberculosis. Tubercle, 47, 370.

Dickinson, J.M. \& Mitchison, D.A. (1966b) Short-term intermittent chemotherapy of experimental tuberculosis in the guinea-pig. Tubercle, 47,381 .

Dickinson, J.M. \& Mitchison, D.A. (1970) Suitability of rifampicin for intermittent administration in the treatment of tuberculosis. Tubercle, 51, 82.

Dickinson, J.M., Ellard, G.A. \& Mitchison, D.A. (1968) Suitability of isoniazid and ethambutol for intermittent administration in the treatment of tuberculosis. Tubercle, 49, 351 .
Hartmann, G., Honikel, K.O., Knüsel, F. \& Nüesch, J. (1967) The specific inhibition of the DNA-directed RNA synthesis by rifamycin. Biochimica et Biophysica Acta, 145, 843.

Sippel, A. \& Hartmann, G. (1968) Mode of action of rifamycin on the RNA polymerase reaction. Biochimica et Biophysica Acta, 157, 218.

Tripathy, S.P. (1970) Madras Study of two once-weekly regimens-laboratory aspects. Bulletin of the International Union Against Tuberculosis, 43, 276.

Tuberculosis Chemotherapy Centre, Madras (1970) A controlled comparison of a twice-weekly and three onceweekly regimens in the initial treatment of pulmonary tuberculosis. Bulletin of the World Health Organisation, 43, 143.

Umezawa, H., Mizuno, S., Yamazaki, H. \& NitTa, K. (1968) Inhibition of DNA-dependent RNA synthesis by rifamycins. Journal of Antibiotics, 21, 234.

Wehrli, W., Knüsel, F., Schmid, K. \& Staehelin, $M$. (1968a) Interaction of rifamycin with bacterial RNA polymerase. Proceedings of the National Academy of Science, 61, 667.

Wehrli, W., Nüesch, J., Knüsel, F. \& Staehelin, M. (1968b) Action of rifamycins on RNA polymerase. Biochimica et Biophysica Acta, 157, 215. 